\title{
Efficient NADH Regeneration by a Redox Polymer- Immobilized Enzymatic System
}

Mengwei Yuan, † Matthew J. Kummer, † Ross D. Milton, †¥ Timothy Quah, † Shelley D.

Minteer ${ }^{*}+$

† Department of Chemistry, University of Utah

315 S 1400 E, Salt Lake City, UT 84112, USA

$\ddagger$ Present Address: Department of Civil and Environmental Engineering, Stanford

University

Clark Center E250, 318 Campus Drive, Stanford, CA 94305, USA

Corresponding Author

*E-mail: minteer@chem.utah.edu 


\section{TABLE OF CONTENTS}

1. Current density recorded for the optimization of mediator-to-enzyme ratio

2. $\mathrm{CVs}$ of denatured $\mathrm{DH} / \mathrm{Cc}-\mathrm{PAA}$ and $\mathrm{DH} / \mathrm{C}_{8}$-LPEI

3. Reactions catalyzed by alcohol dehydrogenase $(\mathrm{ADH})$, lactate dehydrogenase $(\mathrm{LaDH})$ and glucose dehydrogenase (GDH) using produced NADH

4. Stability test for $\mathrm{DH} / \mathrm{Cc}-\mathrm{PAA}$ biocathode

5. Production of methanol by formaldehyde dehydrogenase (FLDH) and alcohol dehydrogenase $(\mathrm{ADH})$ in an enzymatic cascade

1. Current density recorded for the optimization of mediator-to-enzyme ratio

Table S1. Experimental optimization of mediator-to-enzyme ratio

\begin{tabular}{|c|c|c|c|c|}
\hline Mediator-to-enzyme ratio & $60: 0.5$ & $60: 1$ & $60: 1.5$ & $60: 2$ \\
\hline Relative current density $(60: 1=1)$ & 0.89 & 1 & 1.01 & 1.01 \\
\hline
\end{tabular}

\section{CVs of denatured $\mathrm{DH} / \mathrm{Cc}-\mathrm{PAA}$ and $\mathrm{DH} / \mathrm{C}_{8}$-LPEI}



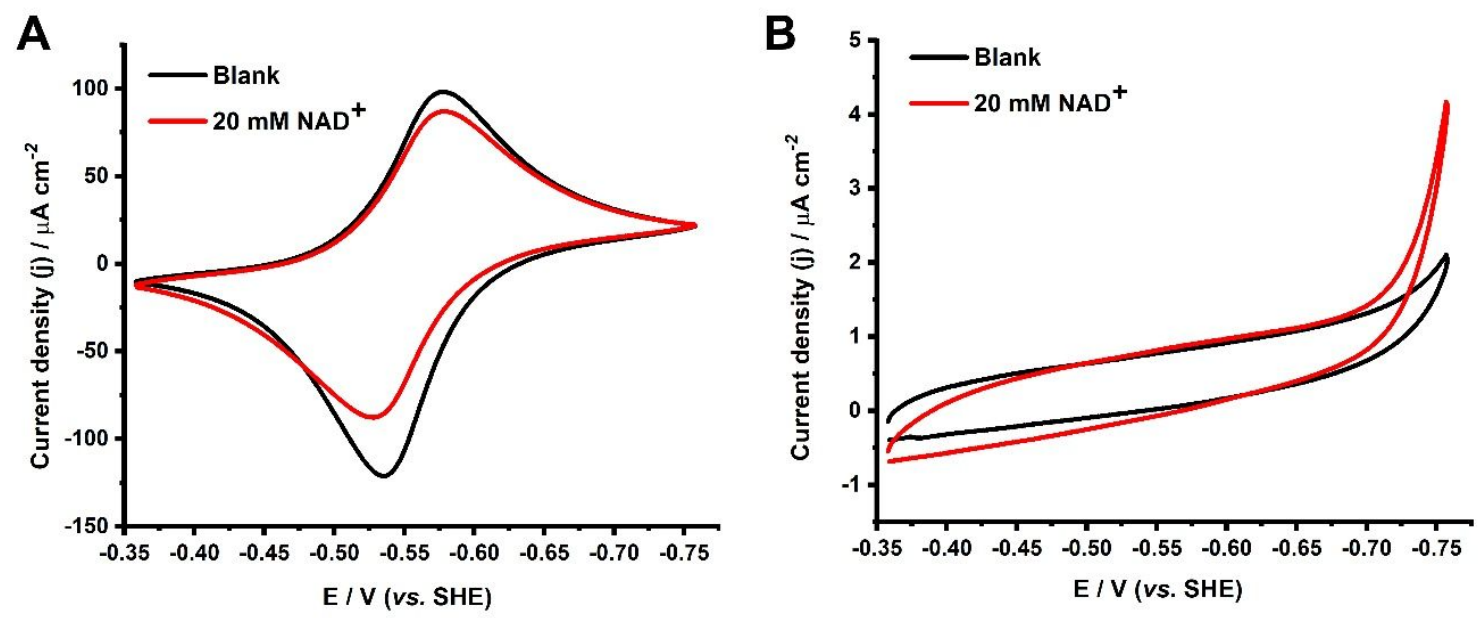

Figure S1. (A) Representative CV of the heat-denatured DH/Cc-PAA bioelectrode without (blank) or with (red) $20 \mathrm{mM} \mathrm{NAD}^{+}$. (B) Representative $\mathrm{CV}$ of $\mathrm{DH} / \mathrm{C}_{8}$-LPEI bioelectrode without (blank) or with (red) $20 \mathrm{mM} \mathrm{NAD}^{+}$. CVs were conducted at a scan rate of $2 \mathrm{mV} \mathrm{s}^{-1}$ in $0.1 \mathrm{M}$ citrate/phosphate buffer ( $\mathrm{pH} 7.0)$.

3. Reactions catalyzed by alcohol dehydrogenase (ADH), lactate dehydrogenase (LaDH) and glucose dehydrogenase (GDH) using produced NADH
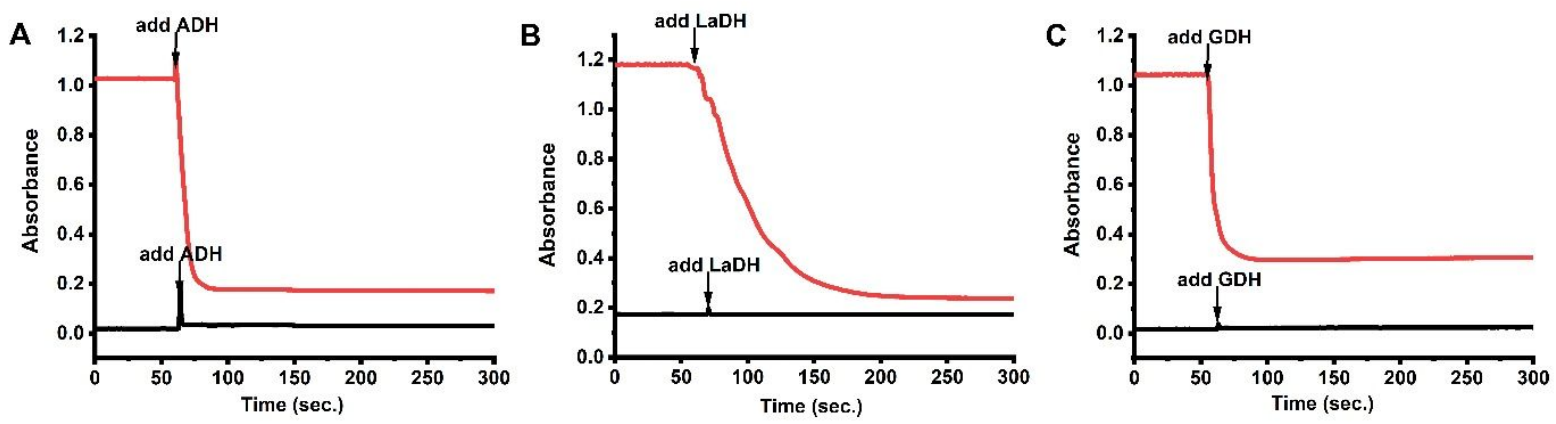

Figure S2. Monitoring UV-Vis absorbance at $340 \mathrm{~nm}$ of electrolyte before (black) and after (red) bulk electrolysis depicting bioactive 1,4-NADH consumption by alcohol dehydrogenase (A), lactate dehydrogenase (B) and glucose dehydrogenase (C) in the presence of their corresponding substrates.

\section{Stability test for DH/Cc-PAA biocathode}



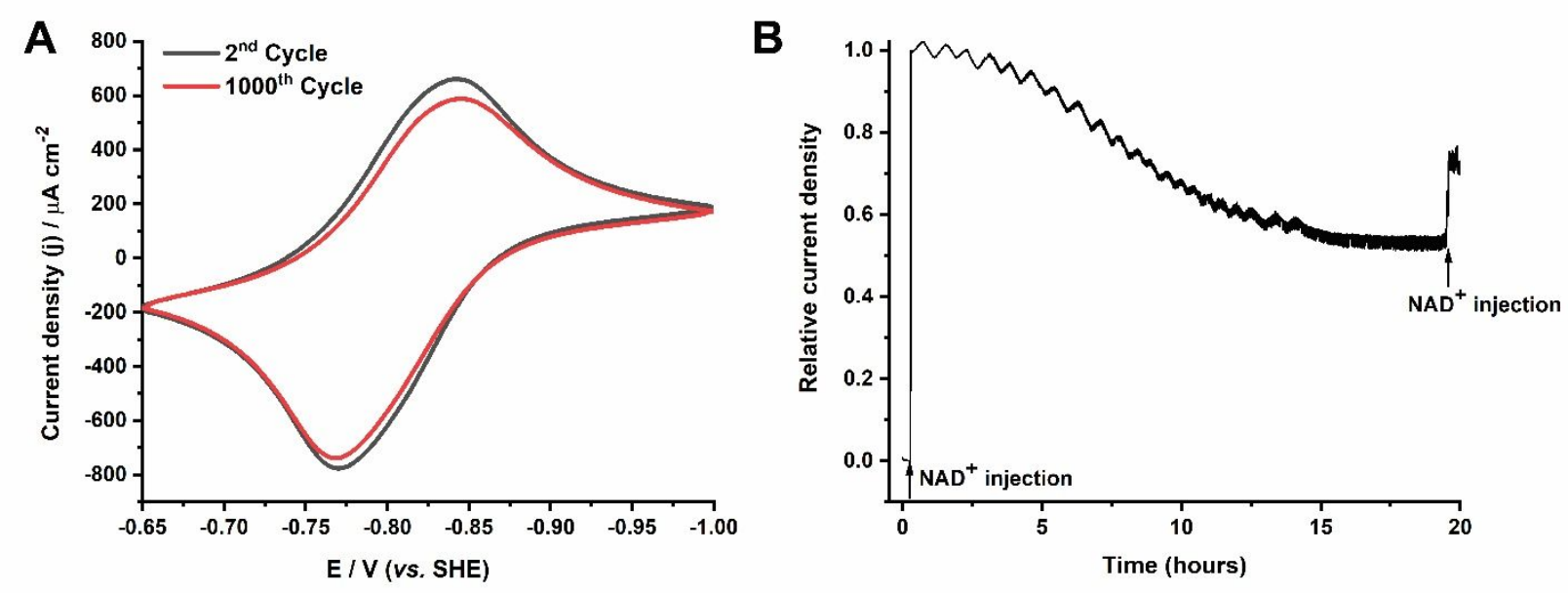

Figure S3. (A) Representative cyclic voltammograms of DH/Cc-PAA electrodes, showing the $2^{\text {nd }}$ cycle and the $1000^{\text {th }}$ cycle. Experiments were performed in $0.1 \mathrm{M}$ citrate/phosphate buffer $(\mathrm{pH} 7.0)$ at a scan rate of $100 \mathrm{mV} / \mathrm{s}$. (B) Continuous NADH regeneration by constant amperometric i-t analysis using DH/Cc-PAA bioelectrode for 20 hours. Applied potential: - $-0.66 \mathrm{~V} v s$. SHE. $50 \mathrm{mM}$ $\mathrm{NAD}^{+}$(final concentration) was injected to electrolyte.

5. Production of methanol by formaldehyde dehydrogenase (FLDH) and alcohol dehydrogenase (ADH) in an enzymatic cascade

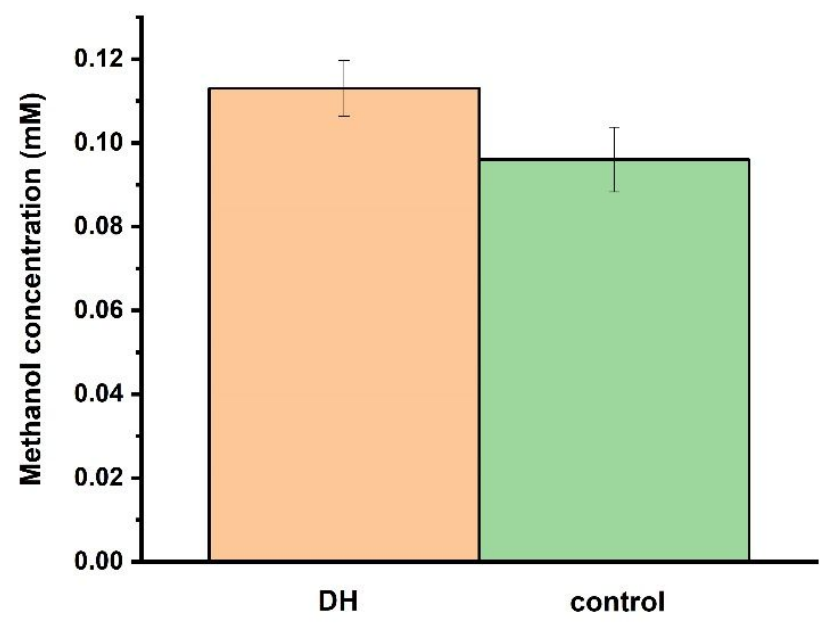

Figure S4. Production of methanol from formate by FLDH and ADH in the absence (control) and presence $(\mathrm{DH})$ of the active NADH regeneration system. Bulk electrolysis was carried out with $0.2 \mathrm{mg} \cdot \mathrm{mL}^{-1} \mathrm{ADH}, 1.2 \mathrm{mg} \cdot \mathrm{mL}^{-1} \mathrm{FLDH}, 100 \mathrm{mM}$ NADH and $50 \mathrm{mM}$ formate in 
citrate/phosphate buffer ( $\mathrm{pH} 7.0$ ) for 24 hours. Applied potential: $-0.66 \mathrm{~V} v s$. SHE. 